\title{
A case of anti-NMDA receptor encephalitis with ADEM-like clinical/MR findings
}

\author{
Jia Liu, Huan Yi, Li Xu, Min Li, Xuan Wang, Fu-Hua Peng \\ Multiple Sclerosis Center, Department of Neurology, the Third Affiliated Hospital of Sun Yat-Sen University, Guangzhou 510630, Guangdong, China.
}

Correspondence to: Dr. Fu-Hua Peng, Multiple Sclerosis Center, Department of Neurology, the Third Affiliated Hospital of Sun Yat-Sen University, Tian He Road No. 600, Guangzhou 510630, Guangdong, China. E-mail: pfh93@163.com

How to cite this article: Liu J, Yi H, Xu L, Li M, Wang X, Peng FH. A case of anti-NMDA receptor encephalitis with ADEM-like clinical/MR findings. Neuroimmunol Neuroinflammation 2016;3:257-9.

Article history:

Received: 05-06-2016

Accepted: 20-10-2016

Published: 18-11-2016

Key words:

N-methyl-D-aspartate,

encephalitis,

acute disseminated

encephalomyelitis

\section{ABSTRACT}

In recent years, anti-N-methyl-D-aspartate receptor (NMDAR) encephalitis overlapping with demyelinating disorders has attracted more and more attention. The case is about a 52-yearold woman with anti-NMDAR encephalitis presenting acute disseminated encephalomyelitis (ADEM)-like clinical/magnetic resonance (MR) findings. Here, the authors report this case and briefly review her MR evolution and the conditions of her prognosis. The recognition that patients with anti-NMDAR encephalitis may have demyelinating disorders, simultaneously or sequentially, is important. Otherwise, a high dose of steroid treatment with several courses could obtain good effect, even if given in the late phase.

\section{INTRODUCTION}

Anti-N-methyl-D-aspartate receptor (NMDAR) encephalitis is a severe autoimmune encephalitis. Patients usually present with psychiatric/behavioral change, dyskinesia, memory deficit, autonomic instability, disorders of consciousness, and even lifethreatening conditions. ${ }^{[1,2]}$ Anti-NMDAR encephalitis has been recognized in patients of all ages, but more frequently in children, with or without teratoma, and young adults. ${ }^{[3]}$ In recent years, anti-NMDAR encephalitis overlapping with demyelinating disorders has attracted more and more attention. However, antiNMDAR encephalitis showing acute disseminated encephalomyelitis (ADEM)-like clinical/magnetic resonance (MR) findings is rare.

\section{CASE REPORT}

A 52-year-old Chinese woman presented with fever, headaches, neck rigidity, and apathy. She was treated successively with intravenous acyclovir and dexamethasone (DXM) in small amounts $(10 \mathrm{mg} / \mathrm{day})$ to control the symptoms as if they were from viral meningitis. Over the following weeks, the patient became progressively confused and had difficulty with walking and urinary and fecal incontinence. She was then transferred to our hospital. A clinical diagnosis 
of autoimmune encephalitis was considered, and she was treated with high doses of intravenous methylprednisolone ( $1 \mathrm{~g} /$ day for 3 days, $0.5 \mathrm{~g} /$ day for 2 days, $0.25 \mathrm{~g} /$ day for 1 day) with two courses of treatment.

The following tests were normal or negative: routine blood test, autoantibody screen, anti-neutrophil cytoplasmic antibody, anti-nuclear antibodies, antibodies related to paraneoplastic neurologic system diseases, acute flaccid paralysis, thyroid biochemistry and antibodies, HIV, CA-125, chest X-ray, electrocardiograms, abdomen and pelvic ultrasound, HBSAg (+), and PETCT showed tumor-negative. Serum and cerebrospinal fluid (CSF) tested positive for anti-NMDAR (titers 1:10) (semiquantitative indirect fluorescent antibody, EUROIMMUN Laboratories). On admission, lumbar puncture (LP) initially showed CSF with a mildly raised protein of $0.51 \mathrm{~g} / \mathrm{L}$, with $60 \times 10^{6} / \mathrm{L}$ white blood cells, $2.16 \mathrm{mmol} / \mathrm{L}$ glucose. PCR for HSV, EBV, CMV in CSF, and bacterial cultures of the CSF were negative. On repeat testing 2 weeks later, LP showed the protein had normalized, a white cell count of $18 \times 10^{6} / \mathrm{L}$, and $3.72 \mathrm{mmol} / \mathrm{L}$ glucose. Serum anti-neuromyelitis optica (NMO)/aquaporin-4 (AQP4) antibody was negative. Serum and CSF oligoclonal bands were positive. Magnetic resonance imaging (MRI) brain scans showed multiple areas of T2 hyperintensity within 1 month after onset and gradually evolving higher signals in the cerebral hemispheres, medulla, cerebellum, and C1-T6 spinal cord. MR scans showed disseminated demyelination lesions on T2 imaging within 1.5 months after onset [Figure 1A-D]. Two months following the onset of fever and headache she was given high doses of intravenous methylprednisolone ( $1 \mathrm{~g} /$ day for 3 days, $0.5 \mathrm{~g} /$ day for 2 days, $0.25 \mathrm{~g} /$ day for 1 day) for two periods of treatment. She improved significantly, could walk slowly and feed herself, had no fever, but had slow reactions and difficulty swallowing. After discharged from our hospital, within 3 months after onset, she had a very good recovery with only some residual dysphagia. Repeat serum and CSF NMDAR-Ab titers were 1:1. Repeat MR scans were clearly improved [Figure 1E-H].

\section{DISCUSSION}

Anti-NMDAR encephalitis is characterized by psychiatric disturbance, seizures, movement disorders, reduced consciousness, and positive NMDA receptor antibodies. ${ }^{[2]}$ In recent years, several articles show that patients with anti-NMDAR encephalitis may develop concurrent or separate episodes of demyelinating disorders, ${ }^{[4]}$ such as neuromyelitis optica spectrum disorder, multiple sclerosis and other demyelinating disorders. Attention should be paid when patients with demyelinating disorders have cooccurring mental disorders, and autonomic instability; because such unusual symptoms may overlap anti-NMDAR encephalitis. There are several articles about this. ${ }^{[5]}$ Here, we report a middle-aged woman with NMDARAbs and clinical and radiologic evidence of ADEM, as well as follow-up after treatment.

Most patients with anti-NMDAR encephalitis will have complete or near-complete recovery. However,
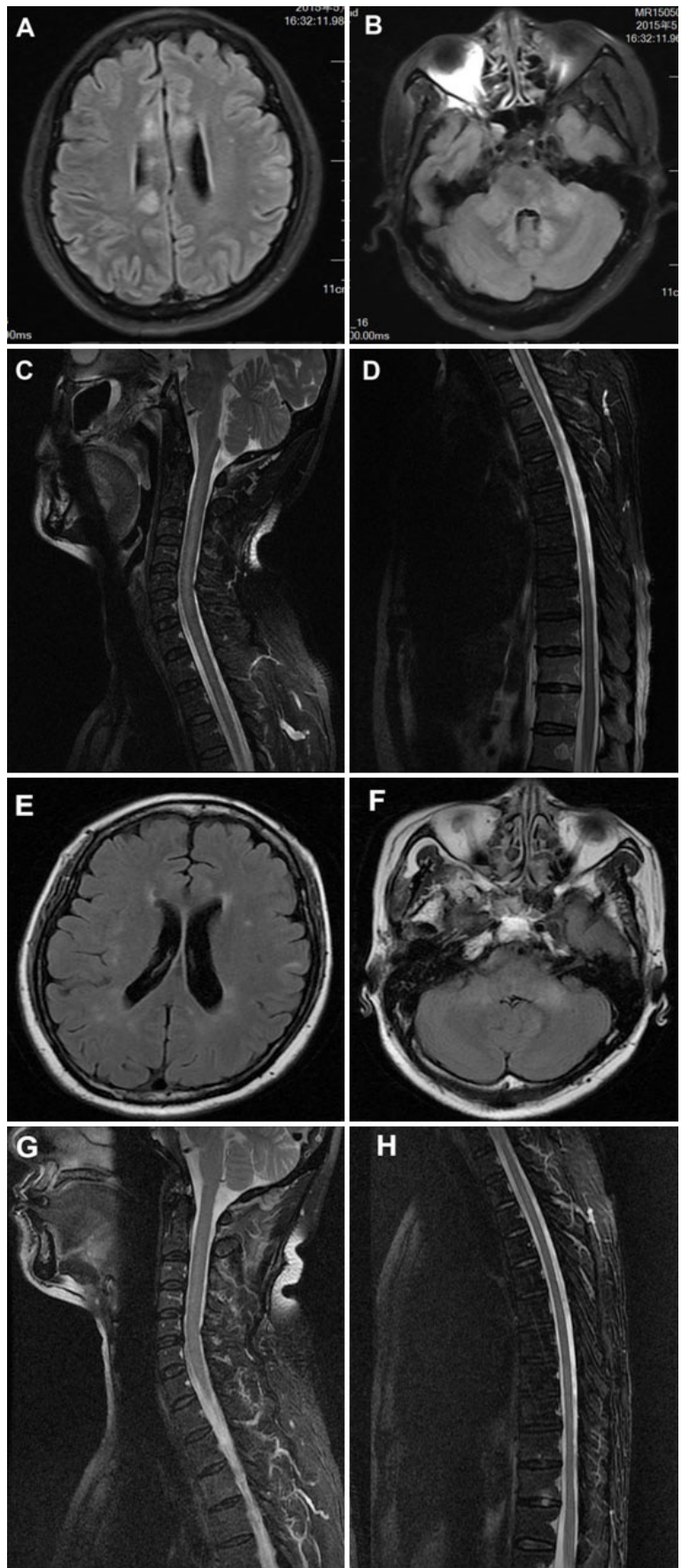

Figure 1: Magnetic resonance imaging (T2 flair) (A-D) disseminated demyelination lesions intracranial and spinal cord within 1.5 months after onset; $(\mathrm{E}-\mathrm{H})$ within 3 months after onset (in which she was treated with high dose intravenous methylprednisolone) 
if it is concurrent with demyelination, there are more deficits, and more intense immunotherapies are often required. ${ }^{[2]}$ Therefore, awareness that anti-NMDAR encephalitis and a demyelinating disorder may occur in the same patient is important for facilitating timely diagnosis and treatment. The pathogenic mechanism of anti-NMDAR encephalitis and demyelinating disorders coexisting is unknown. Several active immune mechanisms may likely play. One may be that functional NMDARs are composed of 5 different subunits as GRIN1, GRIN2A, GRIN2B, GRIN2C and GRIN2D, and these subunits may be associated with demyelinating disorder ${ }^{[6]}$ Additionally, Lipton's ${ }^{[7]}$ work showed that oligodendrocytes and myelin contain NMDAR and that molecular mimicry or immune crossreaction might be involved ${ }^{[8]}$ in pathogenesis. However, the exact relationship between NMDAR antibodies and myelin dysfunction still needs more study.

Conventional treatments of anti-NMDAR encephalitis include corticosteroids, intravenous immunoglobulin (IVIG), and plasma exchange (TPE). These three treatments are considered "first-line" therapies for anti-NMDAR encephalitis. ${ }^{[9]}$ But, in fact, IVIG and TPE are expensive or hard to get in some countries, so hormone therapy is very important.

Our case is notable for the simultaneous occurrence of anti-NMDA receptor encephalitis with ADEM-like clinical/MR features, where, after given a high dose of steroid treatment, the patient had a good prognosis. The patient's first signs were symptom of encephalitis: fever, headaches, and mental abnormalities that could not be controlled with DXM $10 \mathrm{mg} / \mathrm{day}$ and got worse. Gradually, she developed features of disseminated encephalomyelitis: confusion, difficulty walking, and urinary and fecal incontinence. With high doses of hormone therapy for two periods, the above symptoms were improved. Although early and aggressive therapy had not been given to this patient, a high dose of steroid treatment was given in the late phase ${ }^{[10]}$ (1 month after onset), and had a good therapeutic effect. At 3 months after onset, her motor skills, responsiveness, and speech improved rapidly.

In conclusion, it is very important to recognize that patients with anti-NMDAR encephalitis may present as ADEM-like clinical/MRI features, simultaneously or sequentially. In addition, anti-NMDAR antibodies should be assessed in patients with encephalitis or psychiatric symptoms, even when the MRI suggests demyelinating disease. Future studies should pay more attention to these associations. In the mean time, a high dose of steroid treatment could be the first consideration. Even if given in the late phase, there may still be good effects.

\section{Financial support and sponsorship Nil.}

\section{Conflicts of interest}

There are no conflicts of interest.

\section{Patient consent}

Informed consent was obtained from all individual participants included in the study.

\section{Ethics approval}

Data collection in our study involving the patient is consistent with the ethical standards of the institution's ethics committee.

\section{REFERENCES}

1. Viaccoz A, Desestret V, Ducray F, Picard G, Cavillon G, Rogemond V, Antoine JC, Delattre JY, Honnorat J. Clinical specificities of adult male patients with NMDA receptor antibodies encephalitis. Neurology 2014;82:556-63.

2. Dalmau J, Lancaster E, Martinez-Hernandez E, Rosenfeld MR, BaliceGordon R. Clinical experience and laboratory investigations in patients with anti-NMDAR encephalitis. Lancet Neurol 2011;10:63-74.

3. Wandinger KP, Saschenbrecker S, Stoecker W, Dalmau J. AntiNMDA-receptor encephalitis: a severe, multistage, treatable disorder presenting with psychosis. J Neuroimmunol 2011;231:86-91.

4. Titulaer MJ, Hoftberger R, Iizuka T, Leypoldt F, McCracken L, Cellucci T, Benson LA, Shu H, Irioka T, Hirano M, Singh G, Cobo Calvo A, Kaida K, Morales PS, Wirtz PW, Yamamoto T, Reindl M, Rosenfeld MR, Graus F, Saiz A, Dalmau J. Overlapping demyelinating syndromes and anti-N-methyl-D-aspartate receptor encephalitis. Ann Neurol 2014;75:411-28

5. Lekoubou A, Viaccoz A, Didelot A, Anastasi A, Marignier R, Ducray F, Rogemond V, Honnorat J. Anti-N-methyl-D-aspartate receptor encephalitis with acute disseminated encephalomyelitis-like MRI features. Eur J Neurol 2012;19:e16-7.

6. Rossi S SV, Moscatelli A, Motta C, Coghe G, Fenu G, Caillier S, Buttari F, Mori F, Barbieri F, Castelli M, De Chiara V, Monteleone F, Mancino R, Bernardi G, Baranzini SE, Marrosu MG, Oksenberg JR, Centonze D. Opposite roles of NMDA receptors in relapsing and primary progressive multiple sclerosis. PLoS One 2013;8:e67357.

7. Lipton SA. NMDA receptors, glial cells, and clinical medicine. Neuron 2006;50:9-11.

8. Orengo JP PM, Cree BA. Simultaneous serum aquaporin-4 antibody and CSF NMDA receptor antibody-positive encephalitis. Neurol Neuroimmunol Neuroinflamm 2015;2:e101

9. DeSena AD, Noland DK, Matevosyan K, King K, Phillips L, Qureshi $\mathrm{SS}$, Greenberg BM, Graves D. Intravenous methylprednisolone versus therapeutic plasma exchange for treatment of anti-n-methyl-daspartate receptor antibody encephalitis: a retrospective review. J Clin Apher 2015;30:212-6.

10. Turkdogan D, Orengul AC, Zaimoglu S, Ekinci G. Anti-N-methyld-aspartate (Anti-NMDA) receptor encephalitis: rapid and sustained clinical improvement with steroid therapy starting in the late phase. $J$ Child Neurol 2014;29:684-7. 